are given at 9 a.m. daily, and there is rarely any required exercise as late as 5 p.m. Young men from a distance can readily find rooms and good board either in private dwellings or in boarding houses. It is possible to secure accommodations (room and board) for 5 or 6 dollars per week, and for a sum between 6 and ro dollars per week it is still easier to be suited. The other necessary expenses of Jife are moderate.

Are there any Scholarships?-In accordance with the request of the founder of the University, twenty Hopkins scholarships, giving free tuition, are annually conferred upon matriculated undergraduate students from Maryland, Virginia, and North Carolina. In addition to these scholarships, eighteen honorary Hopkins scholarships, yielding 250 dollars and free tuition, are offered to those collegiate students from the three States above-named who pass the matriculation examinations with the most credit. Two scholarships giving free tuition are also open to matriculated students from the district of Columbia. Twenty scholarships yielding 200 dollars, and twenty fellowships yielding 500 dollars are annually open to graduate students.

What Special Opportunities are offered to University Students?-Advanced and graduate students are received with or without reference to their being candidates for a degree, and they are permitted to attend such lectures and exercises as they may select. They are not examined for admission to the University, but each instructor satisfies himself of the attainments of all who wish to follow his guidance before admitting them to his classes.

Systematic courses of instruction, varying every year, are announced in the annual programme. The professors are free to give personal counsel and instruction to those who seek it ; books and instruments adapted to investigation and advanced work have been liberally provided; the system of Fellowships secures the presence of twenty special students imbued with the University spirit, most of them looking forward to academic careers ; seminaries limited to a few advanced students under the guidance of a director have been organised in various subjects ; societies devoted to philology, to mathematical, physical, and natural science, to metaphysics, to history and political science, and to archæology, afford opportunities for the presentation of memoirs and original communications, and there are also clubs for the reading and discussion of biological, physical, and chemical papers; during the year courses of lectures are given by resident and nonresident professors on topics to which they have given special attention; the libraries of the Peabody Institute and Maryland Historical Society, founded for the advantage of scholars, are easily accessible; the issuing, under the auspices of the trustees, of publications devoted to mathematics, chemistry, philology, biology, and history brings the University into advantageous connection with other foundations; special libraries connected with the seminaries bring the most important works within easy reach of the student, and the University reading-room, which is constantly open, is liberally supplied with new and with standard books and with the literary and scientific journals of this and other lands.

On what Conditions is the Degree of Doctor of Philosophy Conferred? - The degree of Doctor of Philosophy and Master of Arts is conferred upon candidates who (after having taken their first degree) have pursued University studies, for three years, under approved conditions, have passed the required examinations and presented a satisfactory thesis. At least the last year of study must be spent in this University.

How are the Fellowships Awarded?-Twenty fellowships are annually open to competition, each yielding five hundred dollars and exempting the holder from all charges for tuition. A statement of the rules governing the awards will be sent if requested. Applications for the next year must reach the University before May I, I 886.
Is there what is commonly known as a College Course? There are seven parallel courses, by following any one of which a matriculated student may attain the degree of Bachelor of Arts. This plan combines the advantages of choice and restriction. From the variety of courses laid down, the scholar elects that which he prefers; having made his choice he finds a definite sequence of studies provided for him. The University marks out for those who elect a classical course, such a plan for the reading of Latin and Greek authors, sometimes with a teacher and sometimes privately, as will enable all who follow it to excel in these studies, while it requires that they should also learn to read French and German, and pursue during one year a course in science. It likewise provides a training which is mainly scientific, enabling the student to concentrate his attention chiefly on chemistry, or biology, or mathematics, or physics; but with these studies he must combine the study of languages, history, and philosophy.

Every matriculated student is expected to follow, under the guidance of an adviser to whom he is specially assigned, one of these prescribed courses which are fully described in the Register. Some elect the classical course. Others may concentrate their main attention upon the higher branches of mathematics. Courses are arranged also for those who wish to devote themselves chiefly to chemistry and physics. For those who expect at a later day to take up the study of medicine, there is a special course marked out, in which biology is the dominant subject. Arrangements are also made in other courses for the study of history and political science and of the modern languages and literatures.

What is required for Admission to the College Courses? - Undergraduates who wish to enter, either as matriculates, candidates for matriculation, students in the preliminary medical course, or as special students, must begin by satisfying the University that they have been thoroughly taught the English studies which are usual in good high schools, academies, and private schools, including a knowledge of arithmetic (with the metric system); geography, physical and political; the outlines of the history of the United States; English grammar and composition. The candidate for matriculation must also pass an examination in-

(I) Latin ; (2) Greek (or French and German); (3) mathematics (algebra, geometry, trigonometry, analytical geometry); (4) English ; (5) history ; (6) narural science. Those who do not intend to follow the classical course may offer French and German instead of Greek. A student may be admitted, under certain circumstances, without matriculation.

Can a Student be aided in Completing his Studies for Matriculation?--If a student at his admission passes in a considerable part of the matriculation requirements he may postpone the remainder for a time. If he is well up in algebra and geometry he may join the University classes in trigonometry and analytical geometry; if he is a good scholar in Latin and Greek, but has not read all the authors requisite for matriculation, he may receive instruction in these authors from the University ; if he has not already acquired the elements of French and German he will be aided in doing so, in order that he may enter the courses here provided.

\section{THE HARVARD PHOTOMETR $Y^{1}$}

WE have waited for the second part of this very remarkable volume completing the Harvard Photometry, rather than examine the separate portions piecemeal. There can be no doubt that its appearance is associated with an epoch in the general progress of astronomical science, coincident nearly with the other

${ }^{2}$ Constituting Parts $x$ and 2 of vol. xiv, of the Annals of the Astronomica Observatory of Harvard College. (1885.) 
corresponding advances in connection with the spectroscope and sidereal photography. The three combined constitute a distinct feature in the more modern methods, by which we are gradually becoming better acquainted with the infinite remote. So soon as molecular physics shall have made, as is promised, a like advance, then the infinite minute also will be brought more distinctly within the human ken.

With regard to the Harvard volume on Sidereal Photometry, without unreservedly conceding to it all the accuracy to which it lays claim, it must be gratefully acknowledged that it provides astronomers with a consistent and valuable catalogue of stellar lustre which, in a complete form, had not hitherto existed. It dispenses with the too often unreliable and discordant estimates of the past, and replaces them by scientific measures possessing, to say the least, considerable precision.

The two parts of the volume contain together no less than 512 closely-printed pages, many of them abounding with models of condensation, and constituting in themselves a remarkable instance of sustained and successful scientific labour. They embrace not only the general history of the subject to which the volume refers, but they at the same time combine elaborate criticism and valuable comparisons of the results of preceding labourers in the same field.

In the first part there is given a description of the meridian photometer, with which the measures of comparative lustre of the stars are obtained. In it are most ingeniously combined the more valuable and least dangerous devices which are found in the instruments devised by Sir John Herschel, Steinheil, and Zöllner. Taken as a whole, the instrument may be properly regarded not only as ingenious but as original. Roughly speaking, it consists of two contiguous telescopes placed horizontally nearly in the meridian, each of the object-glasses being armed with a reflecting prism, so that the light from Polaris and any other star may be brought into the same field of view, after having passed through a double-image prism. The images are then viewed through a Nicol prism, and, by means well known to physicists, the light of the one star is reduced by a measurable amount until it is adjudged to be equal to that of the other star.

We trust we may be pardoned if we suggest that this construction of the instrument may possibly be too complicated to admit of that amount of precision in the measures which could be desired, and which might be obtained by simpler means. In fact, it appears from the volume itself, that at the commencement of operations, it was necessary to abandon the results of several months' work with it; and although an improvement in the use of it was subsequently adopted, we think there still remain traces of the possibly inherent difficulty of precise adjustment. The rapidity also with which the equalisation of brightness of each star with that of Polaris is made, seems hardly consistent with the requisite precision. It is to be inferred from the volume itself that as many as forty-eight final determinations, each consisting of four equalisations of the light of a star with that of Polaris, are frequently completed within the hour, in addition to the consumption of time required for finding and identifying the successive stars and adjusting them in the field of view. But, we cannot doubt, this point has been well considered by the Harvard astronomers themselves.

In the determination of the magnitude of a star, it is the usual practice to rest content, generally, with the mean of three determinations. Each determination is made on a different night, and consists of the mean of four equalisations of the lustre of the particular star compared with that of Polaris in the field of the photometer. We venture to think that the general limitation to three only is too restricted for the purposes of accuracy. The reason for this opinion is derived from the fact that on examining the numerous cases in which as many as fifteen determinations of magnitude are made on as many nights, it is very frequently, and in fact generally, possible to find three consecutive determinations which would of themselves, in the mean, lead to a magnitude widely different from that ultimately assigned. Yet these three consecutive sets furnish no circumstance of inter-discordance among themselves which could lead to suspicion, and which might, consistently with the usual practice, have finally settled the magnitude of the star in question. We regard this not as hypercriticism, but as being the only sufficient means at hand for the examination of accuracy furnished by the volume itself.

Independently of the several catalogues containing the results of three years' unremitting labour and persevering skill, the volume abounds with the intercomparison and reduction to one scale of the work achieved in a similar direction by many preceding astronomers. The result is that astronomers who are desirous of information on the subject of stellar brightness, will probably not be disappointed if they turn to the pages of the Harvard Photometry. Combined with a memoir by Prof. Pritchard, contained in vol. xlvii. of the Memoirs of the Royal Astronomical Society, it is perhaps not too much to say that all that is known upon the subject up to the present date will be found easily accessible to the student.

Towards the conclusion of the volume Prof. Pickering has drawn up a very important table, which, though short, must have given him very considerable labour to compute. It contains in one summary a critical comparison of the average results of all the principal catalogues of stellar magnitude hitherto published. The Harvard Photometry is taken as the basis of the comparison, and the difference between the mean or total results of each catalogue and that of the Harvard volume is given. From the inspection of Table lxxxiii. it appears that, taken as a whole, the Harvard measures indicate in the mean a brightness of the stars compared greater than that indicated by the estimates in the Durchmusterung of 'I4 mag., brighter than the mean of the Uranometria Nova of Argelander by 'ro mag.; of Heis by I 2 mag. ; and of Houzeau by II mag. These differences, it will be observed, are all in one direction, and might appear to indicate that there is a generic difference between estimates of star magnitude by the unaided eye, and measures carefully made with a photometer such as is the meridian photometer at Harvard College, because all the estimates are apparently fainter than the measures. But this can scarcely be the true explanation, since the photometric measures also of Seidel, Zöllner, and Peirce indicate, like the eye estimates, a brightness less than that of the American determinations. Moreover, the photometric measures made by Prof. Pritchard at Oxford agree in the mean of the whole, very closely with the eye estimates in the Durchmusterung and the other catalogues. But, whatever the significance of this fact may be, it cannot be doubted that the Harvard volume will ever remain a most valuable addition to our knowledge in an important branch of astronomical science.

\section{U.S. INDUSTRIAL STATISTICS ${ }^{1}$}

TO all who study anxiously social science, this is a very promising publication; its indirect testimony to the advantages of Republican institutions will be weightier to any reflective man than the eloquent tirades that are so usually bestowed upon them. It defines its object to be the stimulation and assistance of the wageworker in his endeavour to reach a higher position. Its information respecting working men is all taken from their own contributions, a dozen pages of small print being filled with verbatim quotations from the replies of workpeople in every trade in the State, who give such I "Sixth Annual Report of the Bureau of Statistics of Labour and Industries of New Jersey," $188_{3} . "$ Trenton: New Jersey, $188_{3}$. 